\title{
Alkaloids from the roots of Stemona saxorum
}

Ya-Zhou Wang, ${ }^{\dagger}$ Chun-Ping Tang,${ }^{\dagger}$ Pham-Huu Dien, ${ }^{\star}$ Yang Ye ${ }^{*}{ }^{\dagger}$

State Key Laboratory of Drug Research, Shanghai Institute of Materia Medica, Chinese Academy of Sciences, 555 Zu-Chong-Zhi Road, Zhangjiang Hi-tech Park, Shanghai 201203, P. R. China, and Department of Organic Chemistry, Faculty of Chemistry, Hanoi National University of Education, 136-Xuanthuy Street, Caugiay District, Hanoi, Vietnam

* To whom correspondence should be addressed. Tel: +86-21-50806726. Fax: +86-21-50807088. E-mail: yye@ mail.shcnc.ac.cn.

${ }^{\dagger}$ Shanghai Institute of Materia Medica, Chinese Academy of Sciences.

Hanoi National University of Education. 


\section{List of supporting information}

S1. ${ }^{1} \mathrm{H}$ NMR spectrum $\left(300 \mathrm{MHz}, \mathrm{CDCl}_{3}\right)$ of the new compound 1

S2. ${ }^{13} \mathrm{C}$ NMR spectrum $\left(100 \mathrm{MHz}, \mathrm{CDCl}_{3}\right)$ of the new compound $\mathbf{1}$

S3. ROESY spectrum $\left(600 \mathrm{MHz}, \mathrm{CDCl}_{3}\right)$ of the new compound $\mathbf{1}$

S4. ${ }^{1} \mathrm{H}$ NMR spectrum $\left(400 \mathrm{MHz}, \mathrm{CDCl}_{3}\right.$ ) of the new compound $2 \quad$ P6

S5. ${ }^{13} \mathrm{C}$ NMR spectrum $\left(100 \mathrm{MHz}, \mathrm{CDCl}_{3}\right)$ of the new compound $2 \quad$ P7

S6. NOESY spectrum $\left(400 \mathrm{MHz}, \mathrm{CDCl}_{3}\right)$ of the new compound $2 \quad$ P8

S7. ${ }^{1} \mathrm{H}$ NMR spectrum $\left(300 \mathrm{MHz}, \mathrm{CD}_{3} \mathrm{OD}\right)$ of the new compound $3 \quad$ P9

S8. ${ }^{13} \mathrm{C}$ NMR spectrum $\left(100 \mathrm{MHz}, \mathrm{CD}_{3} \mathrm{OD}\right)$ of the new compound $\mathbf{3} \quad \mathrm{P} 10$

S9. ROESY spectrum $\left(600 \mathrm{MHz}, \mathrm{CDCl}_{3}\right)$ of the new compound $3 \quad$ P11

S10. ${ }^{1} \mathrm{H}$ NMR spectrum $\left(300 \mathrm{MHz}, \mathrm{CDCl}_{3}\right.$ ) of the new compound 4a $\mathrm{P} 12$

S11. ${ }^{13} \mathrm{C}$ NMR spectrum $\left(100 \mathrm{MHz}, \mathrm{CDCl}_{3}\right)$ of the new compound 4a P13

S12. ROESY spectrum $\left(600 \mathrm{MHz}, \mathrm{CDCl}_{3}\right)$ of the new compound $4 \mathbf{a} \quad \mathrm{P} 14$

S13. ${ }^{1} \mathrm{H}$ NMR spectrum $\left(300 \mathrm{MHz}, \mathrm{CDCl}_{3}\right)$ of the new compound $\mathbf{4 b} \quad \mathrm{P} 15$

S14. ${ }^{13} \mathrm{C}$ NMR spectrum $\left(100 \mathrm{MHz}, \mathrm{CDCl}_{3}\right)$ of the new compound $\mathbf{4 b} \quad \mathrm{P} 16$

S15. ROESY spectrum (600 MHz, $\mathrm{CDCl}_{3}$ ) of the new compound $\mathbf{4 b} \quad \mathrm{P} 17$ 


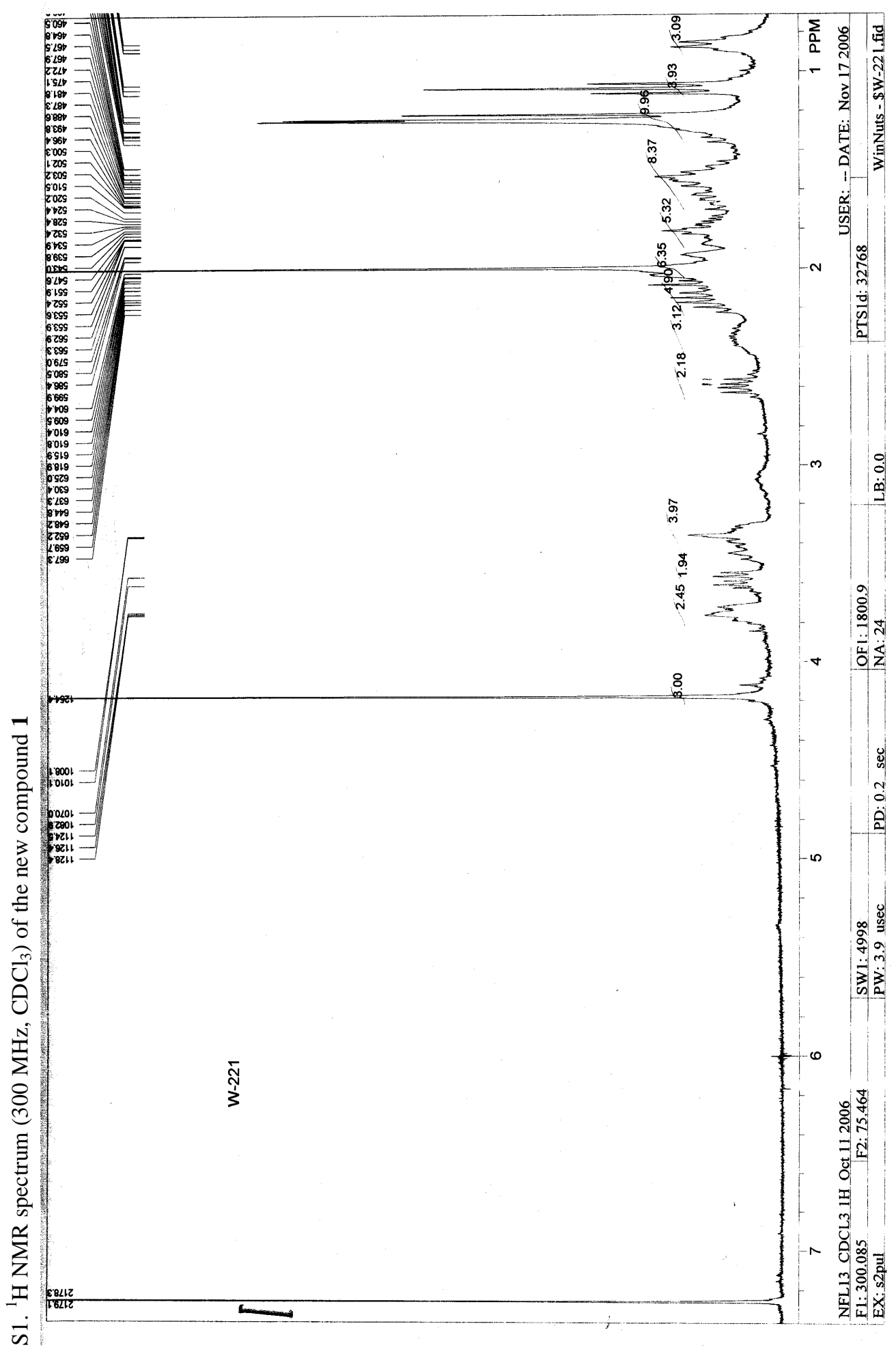




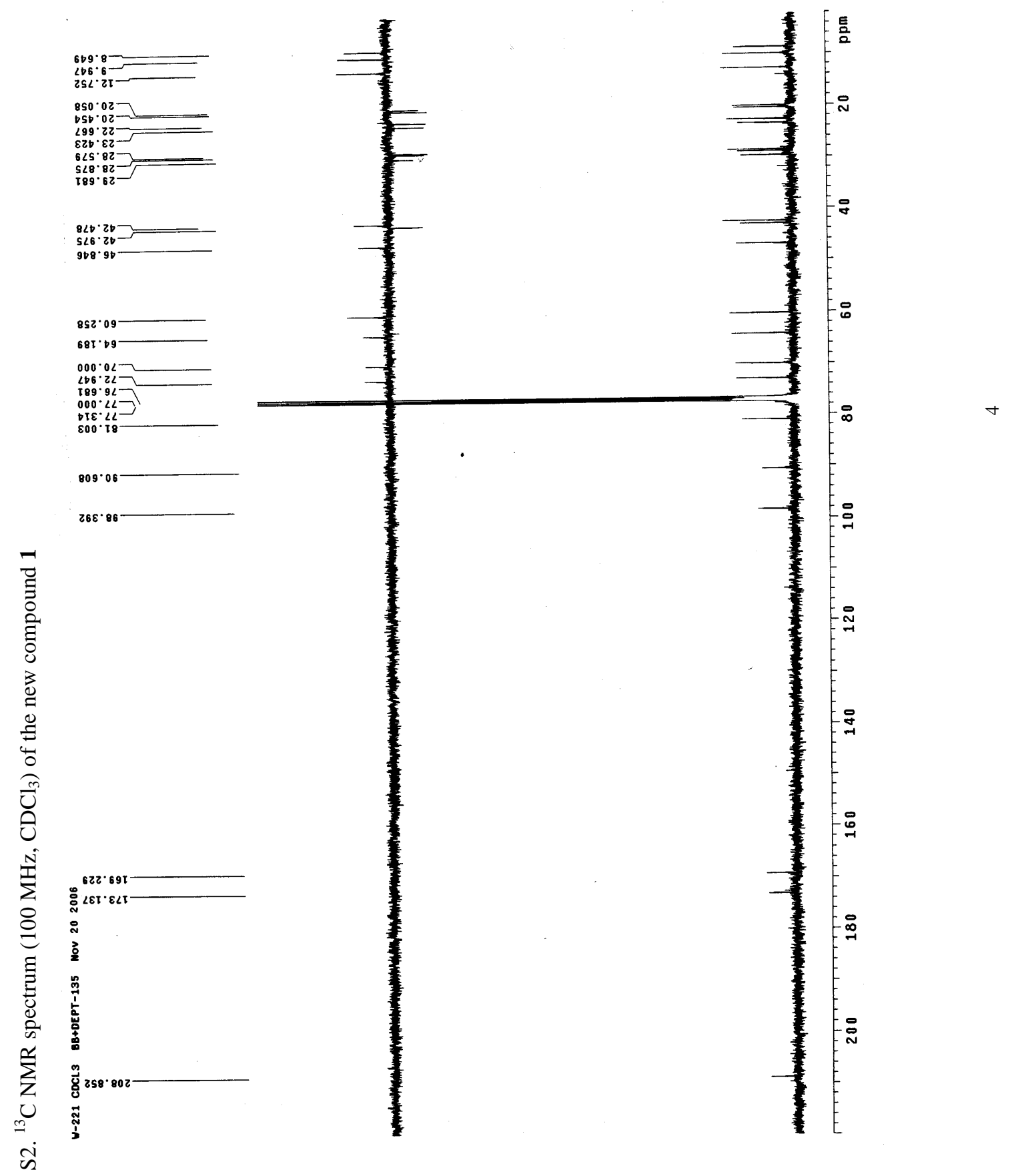




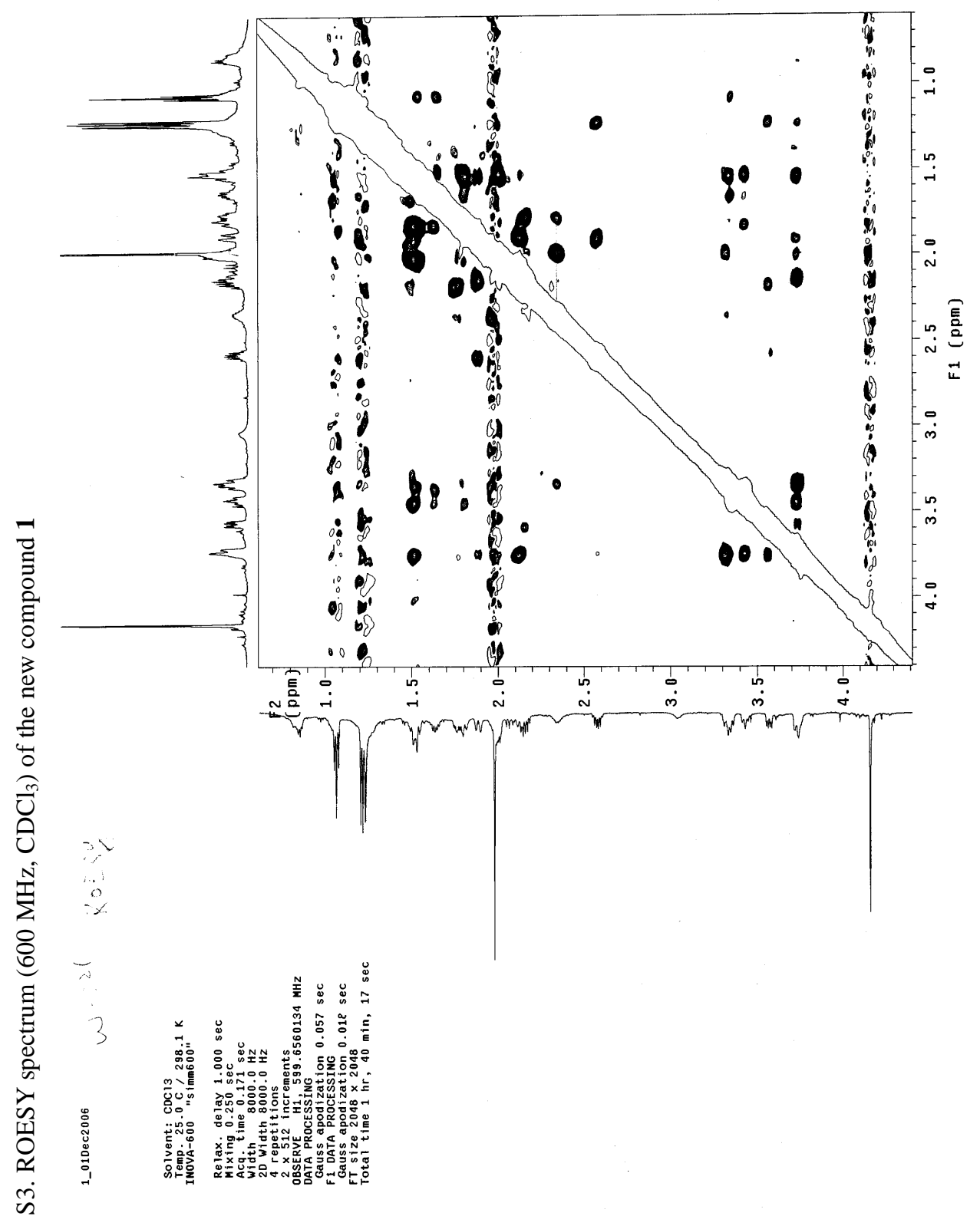




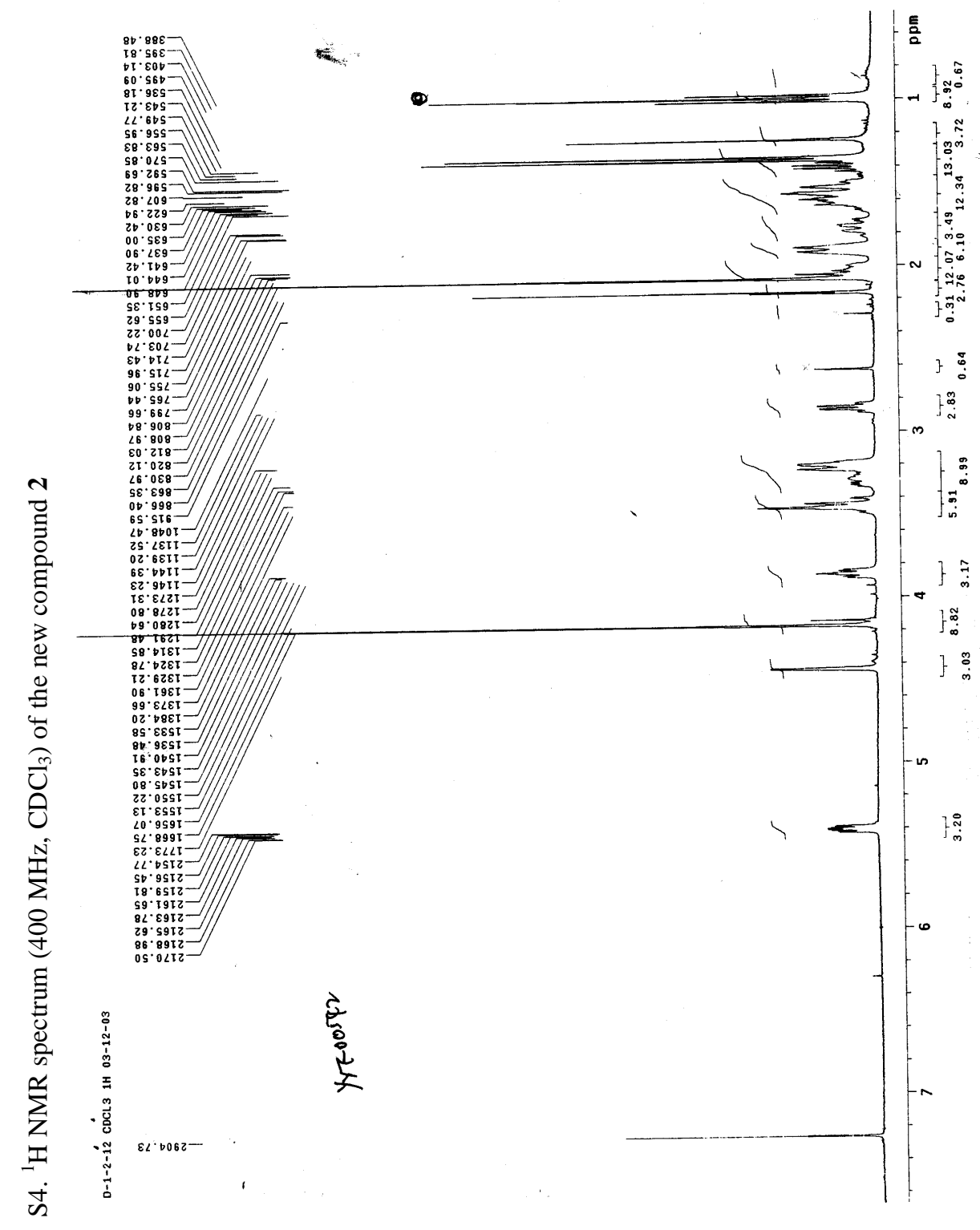




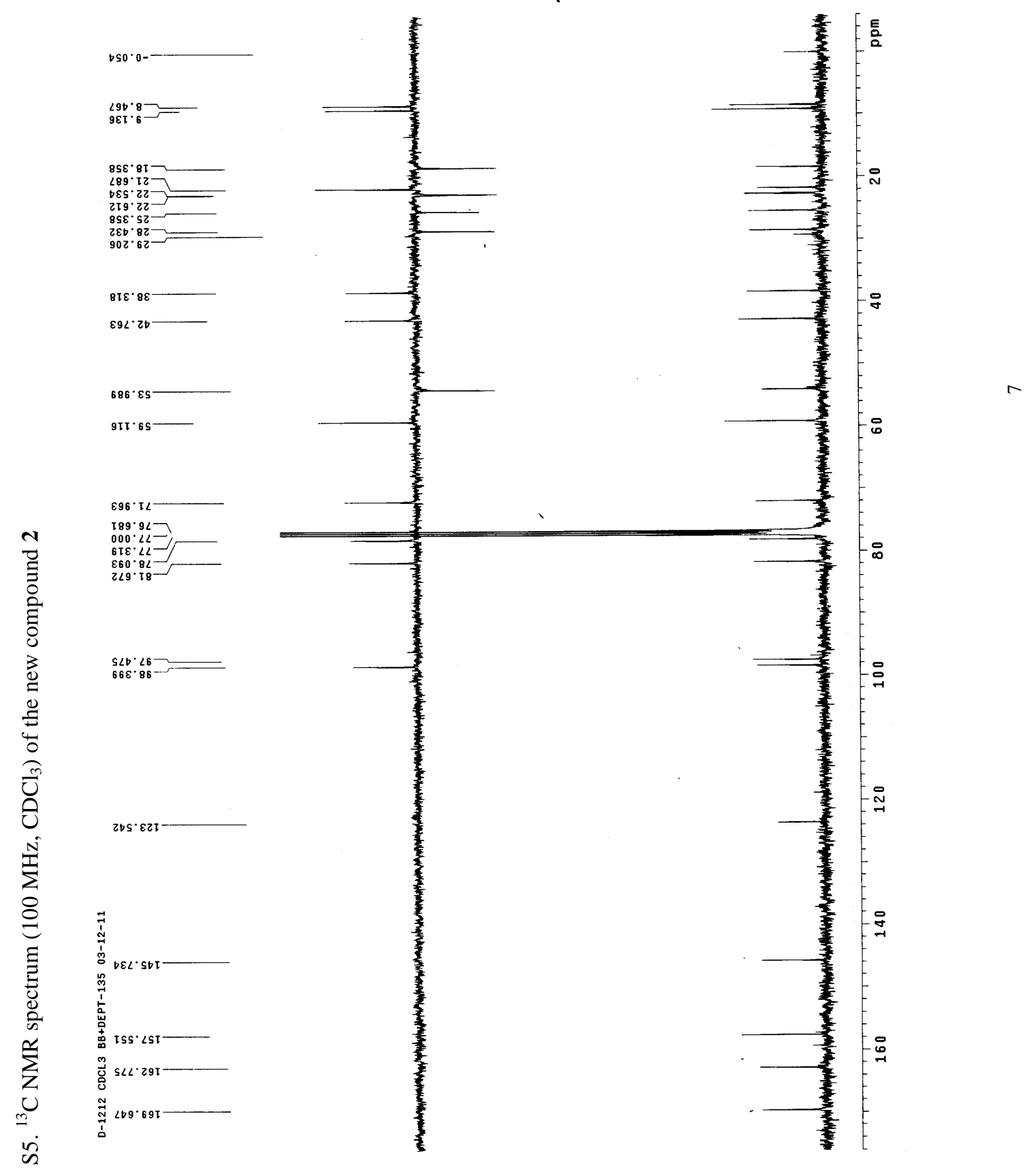




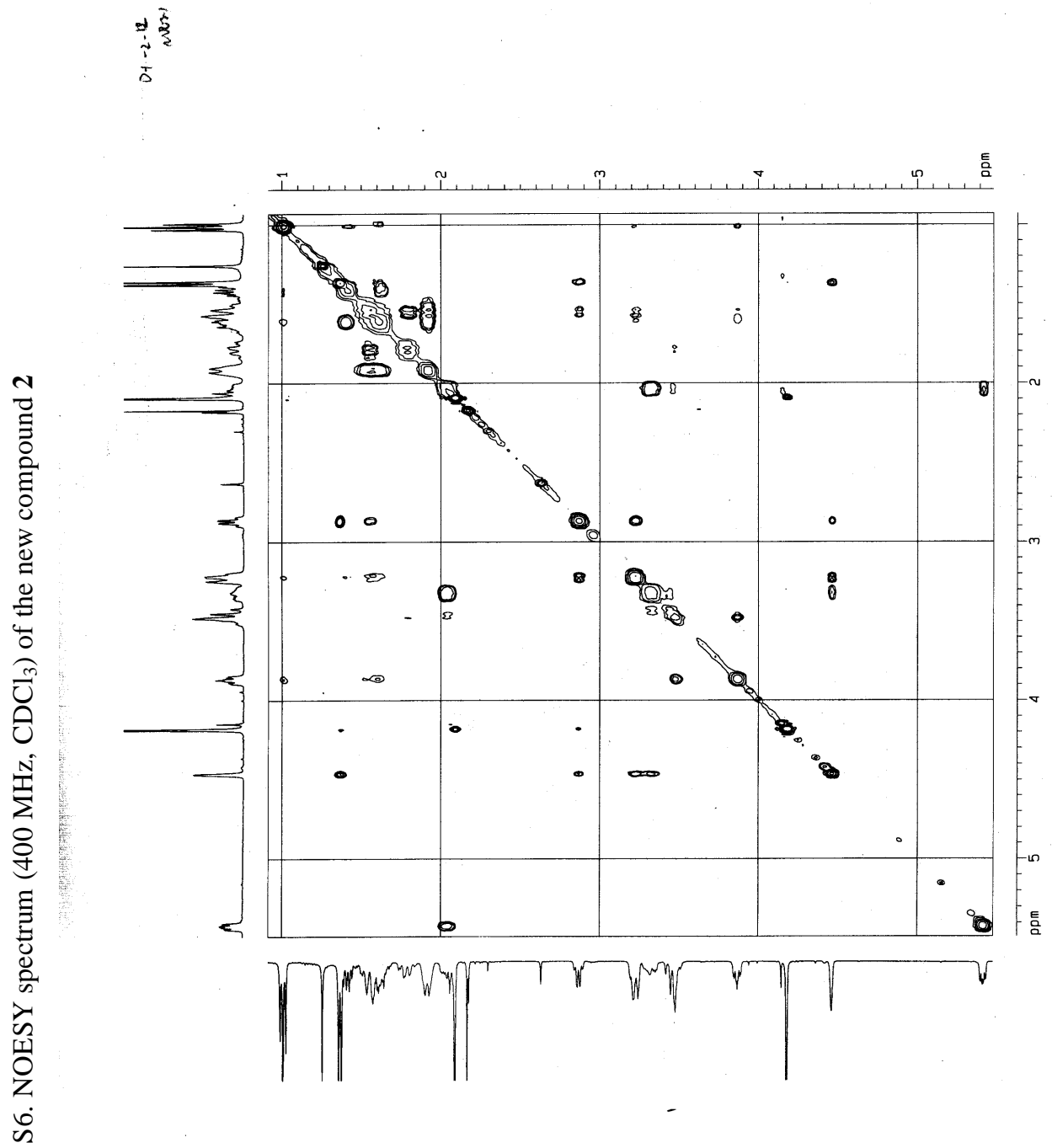




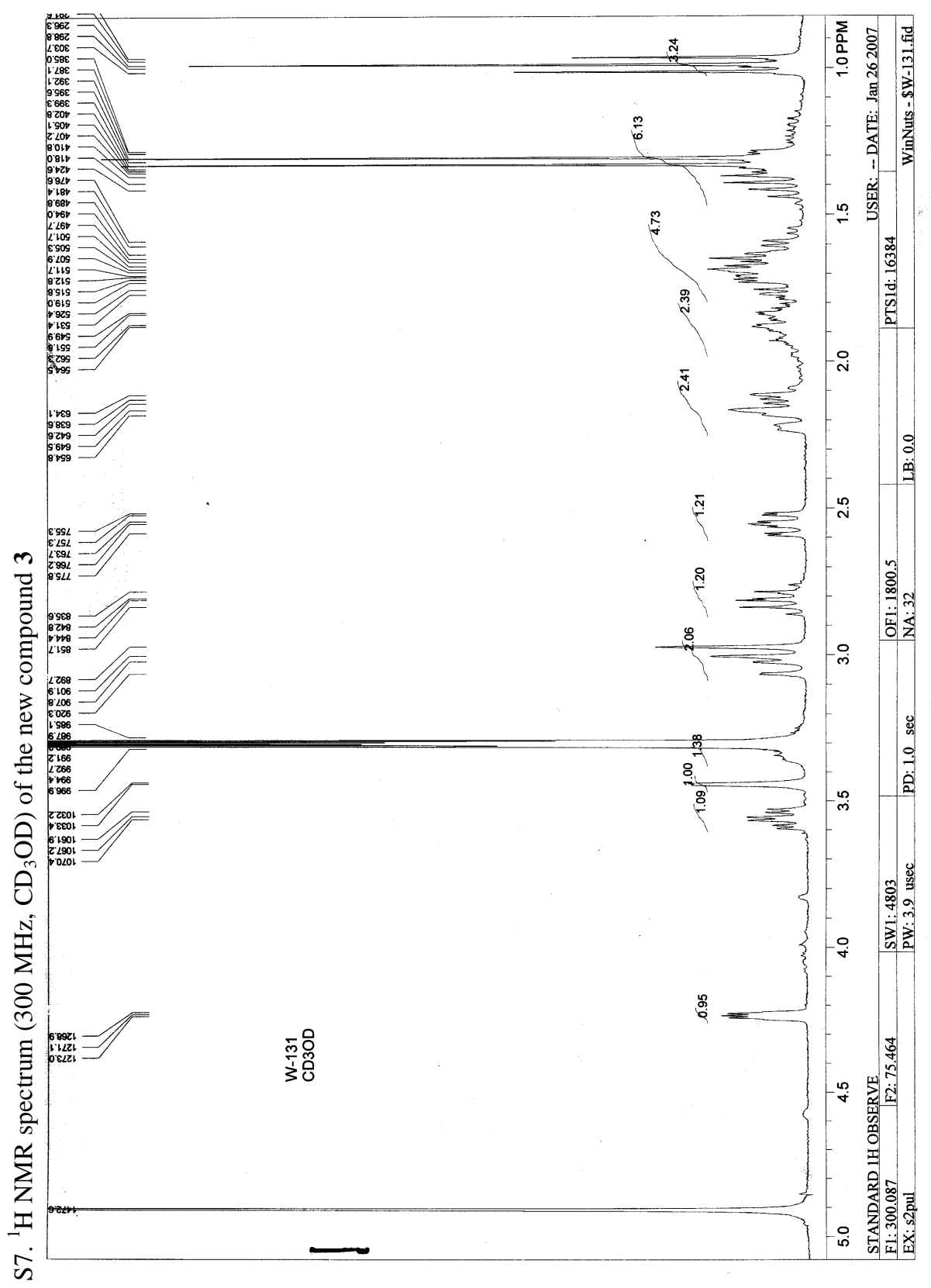



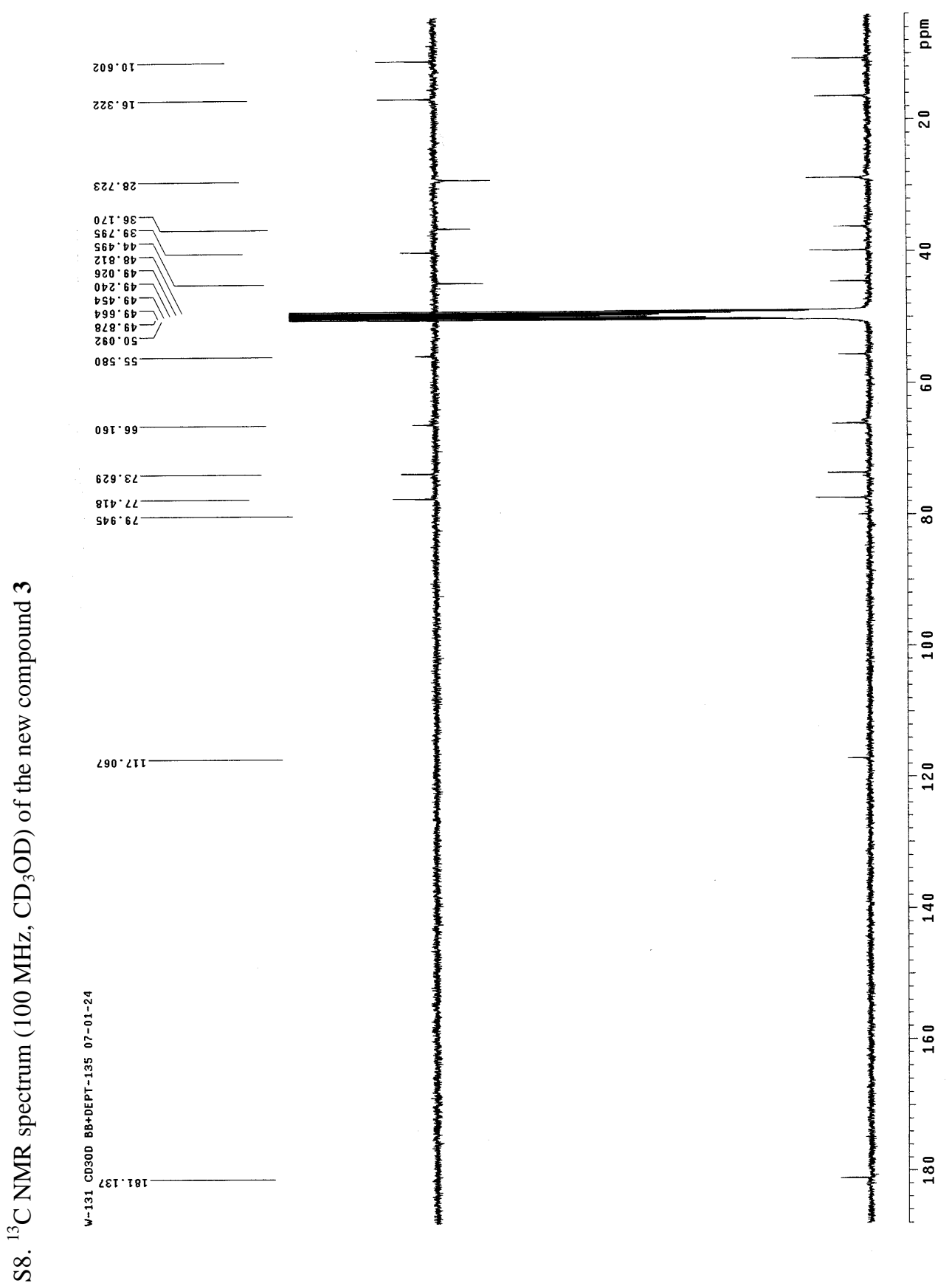


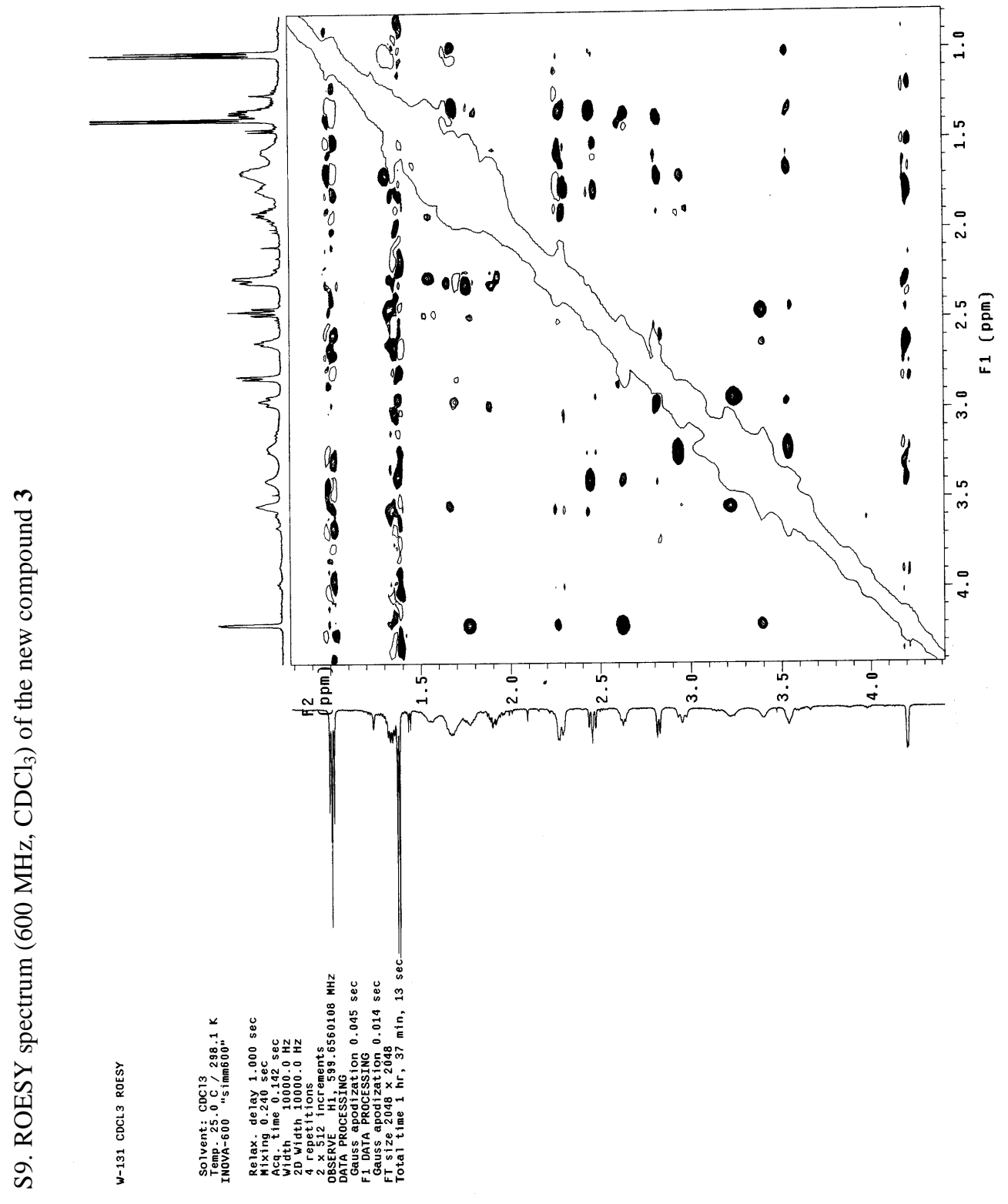




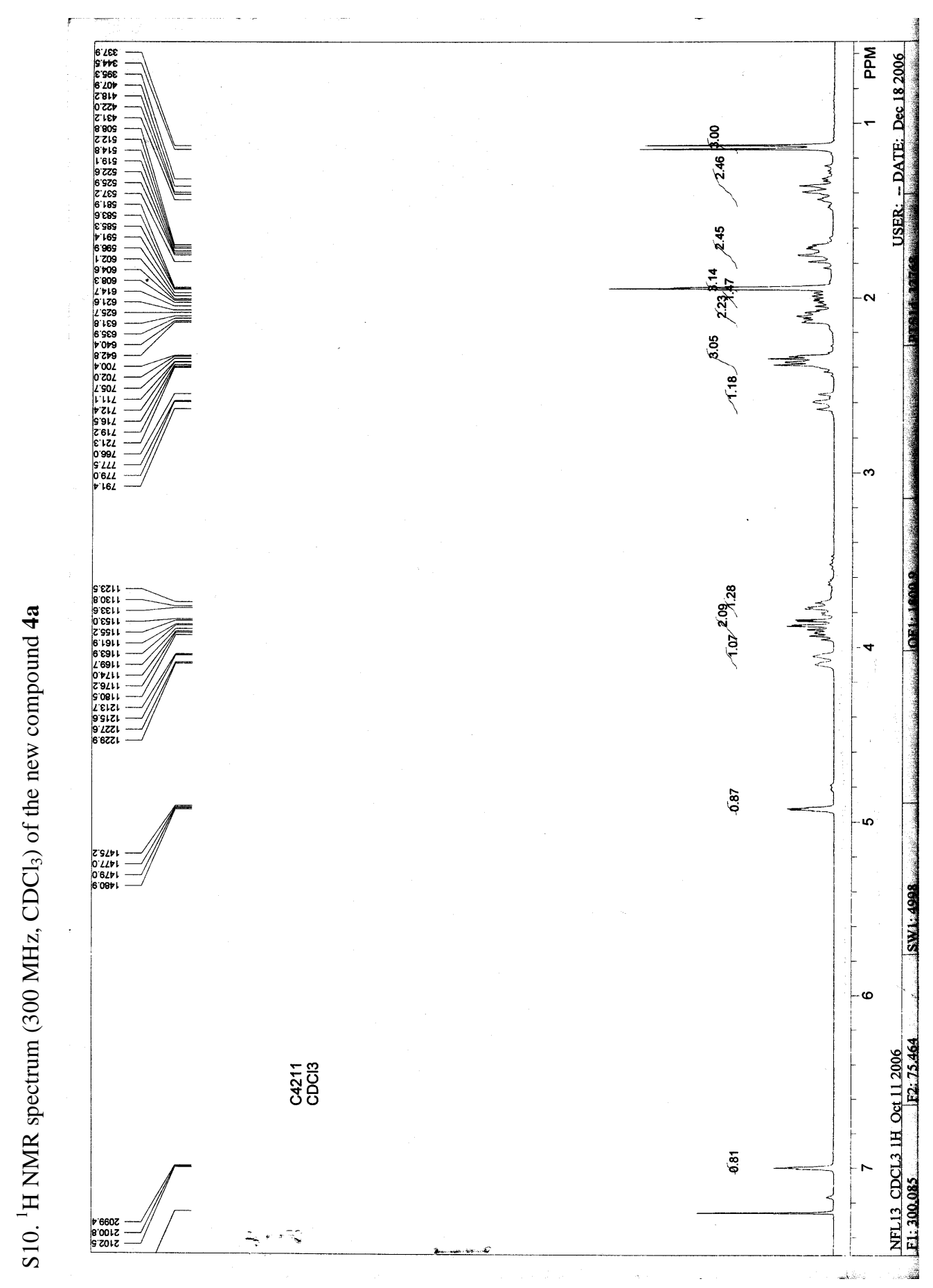




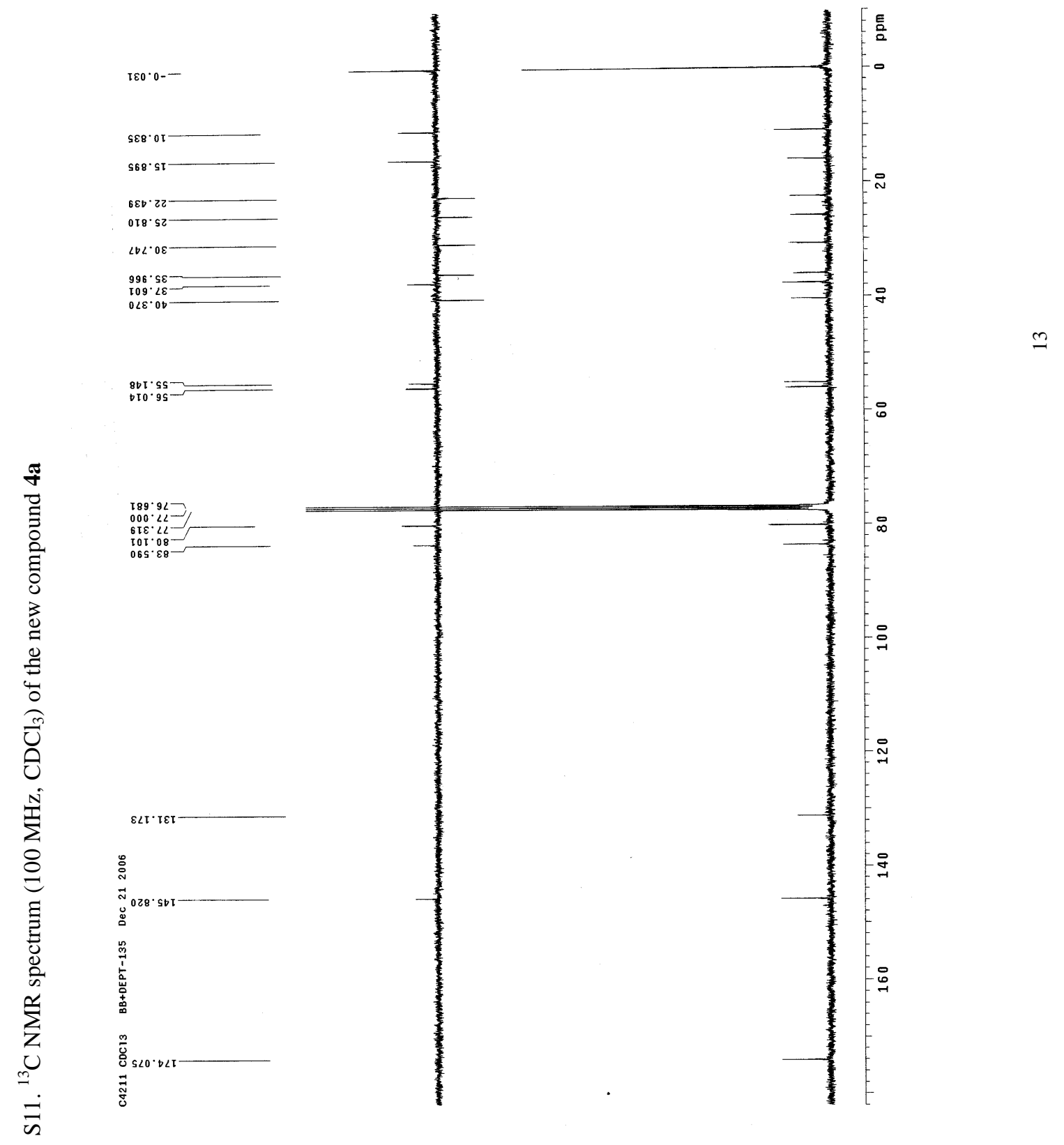




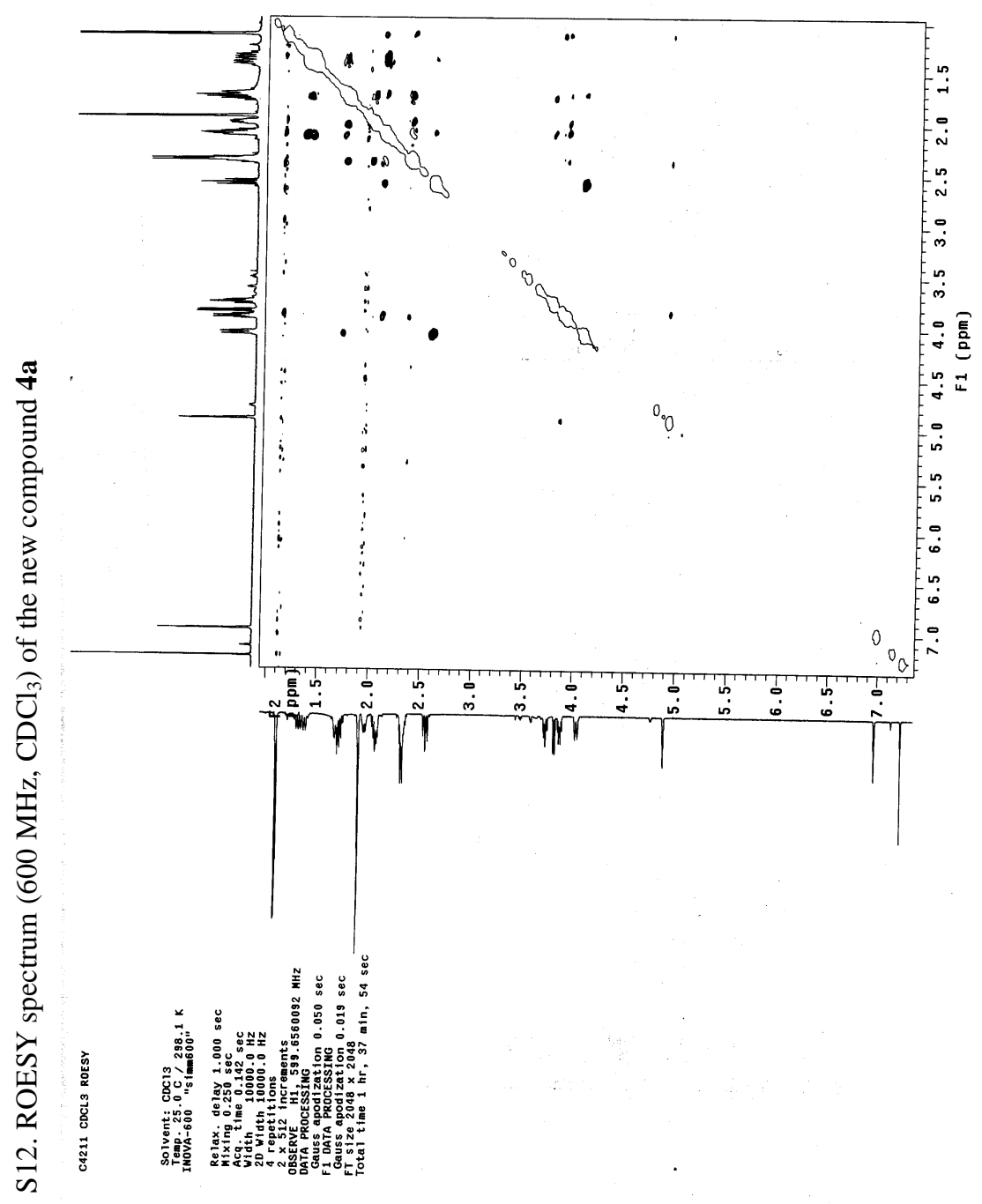




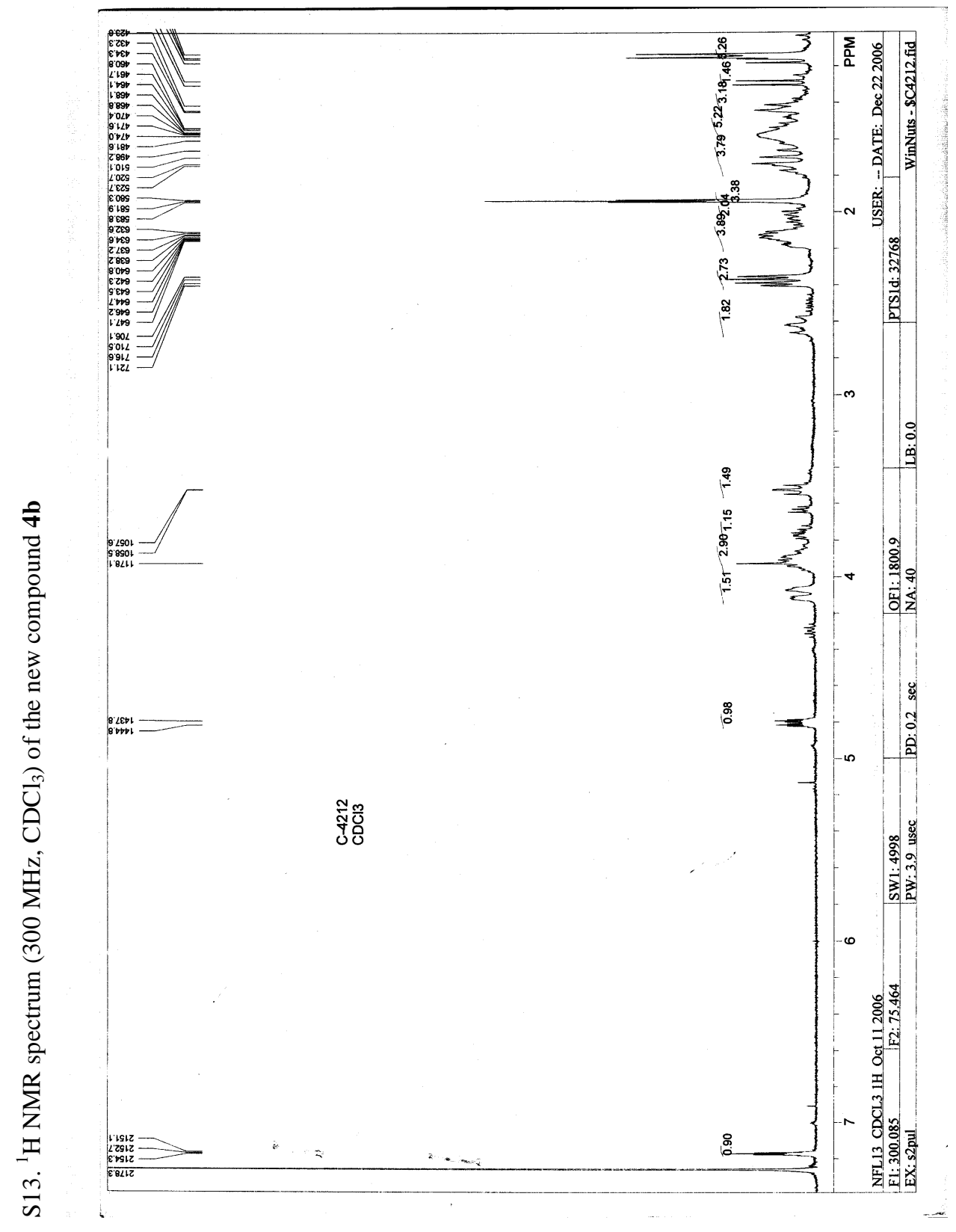




$$
\text { 业 }
$$




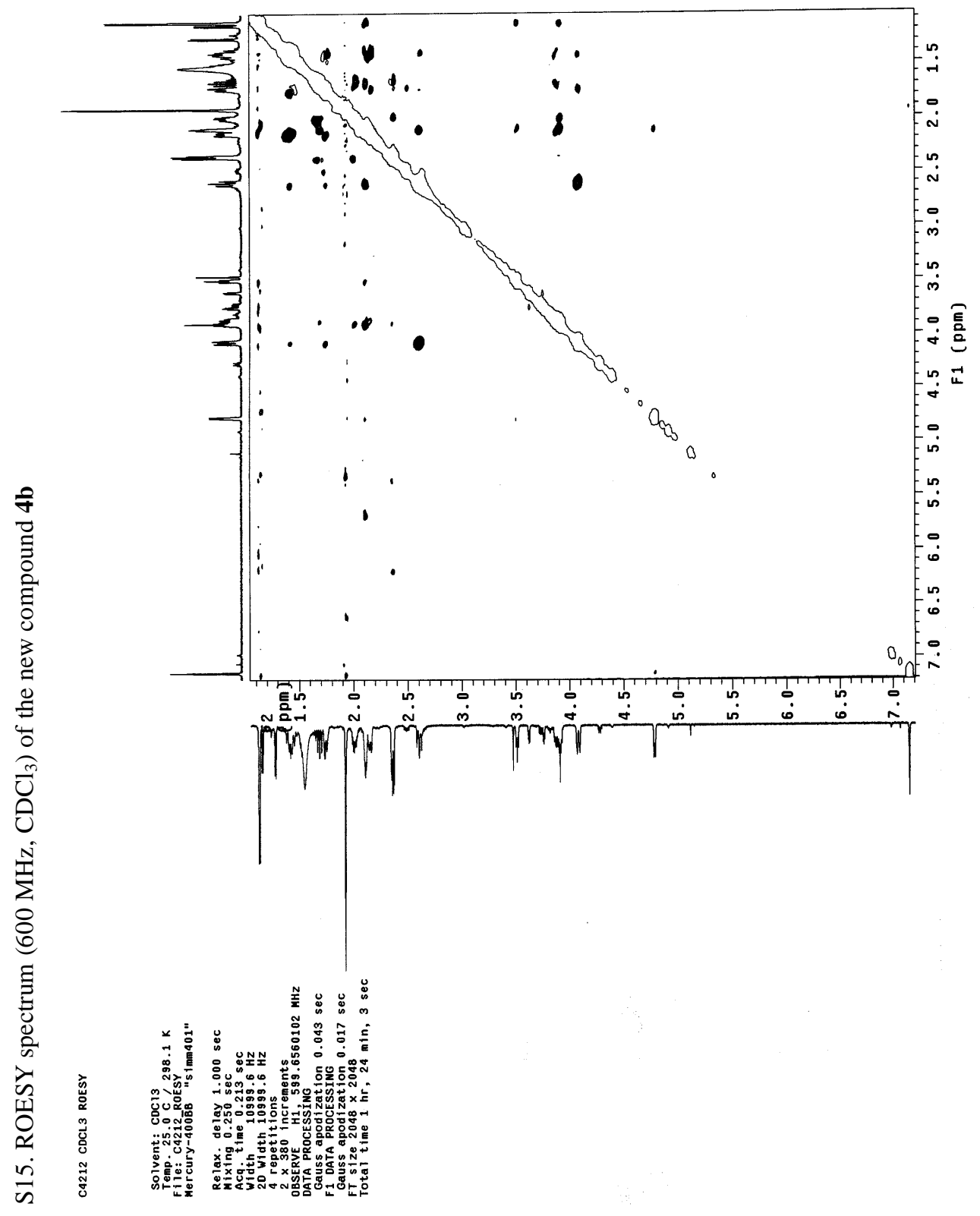

$=$ 